\title{
A caminhada por diferentes propósitos: um estudo na cidade de Cambé-PR
}

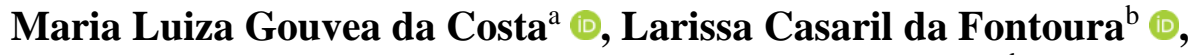 \\ Ana Luiza Favarão Leão ${ }^{c}$ (i) e Milena Kanashiro ${ }^{d}$
}

\author{
${ }^{a}$ Universidade Estadual de Londrina, Departamento de Arquitetura e Urbanismo, Londrina, PR, Brasil. E- \\ mail: marialuizagcosta@gmail.com \\ ${ }^{\mathrm{b}}$ Universidade Estadual de Londrina, Departamento de Arquitetura e Urbanismo, Programa de Pós- \\ Graduação em Arquitetura e Urbanismo, Londrina, PR, Brasil. E-mail: larissa.fontoura@uel.br \\ c Universidade Estadual de Londrina, Departamento de Arquitetura e Urbanismo, Programa de Pós- \\ Graduação em Arquitetura e Urbanismo UEL/UEM, Londrina, PR, Brasil. E-mail: \\ analuiza.favarao@uel.br
}

d Universidade Estadual de Londrina, Departamento de Arquitetura e Urbanismo, Programa de Pós-
Graduação em Arquitetura e Urbanismo UEL/UEM, Londrina, PR, Brasil. E-mail: milena@ @uel.br

Submetido em 28 de janeiro de 2021. Aceito em 11 de janeiro de 2022. https://doi.org/10.47235/rmu.v10i1.193

\begin{abstract}
Resumo. A caminhada é um modo de transporte socialmente equitativo e economicamente viável, que pode ser influenciada por diversos fatores $e$ domínios. Evidências apontam que propósitos de caminhada distintos estão associados a diferentes características do ambiente construído, como a diversidade de usos do solo. Portanto, é necessário o aprofundamento sob o enfoque do motivo pelo qual as pessoas escolhem o deslocamento a pé. $O$ objetivo desta pesquisa é analisar as rotas caminhadas por diferentes propósitos, a partir de dados de distância, duração e uso do solo. Como estratégia metodológica, adotou-se o estudo de caso na cidade de Cambé$P R$, e como tática, utilizou-se a análise correlacional por meio de procedimentos quantitativos e espaciais. Os resultados indicam que os propósitos exercem grande influência no comportamento de caminhada e que funções mandatórias geralmente apresentam comportamentos similares. Ainda, encontrou-se evidências de que a maioria das viagens a pé são realizadas até 800 metros e duram até 15 minutos. A pesquisa contribui para que áreas de influência possam ser identificadas, servindo como parâmetros para estratégias de intervenções urbanas que deem suporte a comportamentos ativos.
\end{abstract}

Palavras-chave. ambiente construído, caminhabilidade, propósito de viagem

\section{Introdução}

Pesquisas da área de saúde estudam a caminhada como a forma mais comum de atividade física entre adultos (Saelens, Sallis e Frank, 2003; Sugiyama et al., 2012), preocupadas com o crescente aumento de doenças crônicas relacionadas à inatividade física (Larsen, El-Geneidy e Yasmin, 2010). Mais recentemente, o surto global da COVID-19 fez com que países buscassem medidas para reduzir seus efeitos (Musselwhite, Avineri e Susilo, 2021), incluindo atributos do ambiente construído. Há evidências de que, em vez de promover o contágio, bairros densos e de uso misto podem reduzir o risco de doenças não transmissíveis e infecciosas, como o coronavírus (Adlakha e Sallis, 2020, Hamidi, Sabouri e Ewing, 2020). 
Além das questões relacionadas à saúde pública, o deslocamento a pé pode estar relacionado com a diminuição dos principais problemas urbanos, tais como expansão urbana, congestionamento, dependência do automóvel e mudanças climáticas (Ewing e Cervero, 2010). Como consequência, estratégias de desenvolvimento urbano sustentável, como o Novo Urbanismo, o Crescimento Urbano Inteligente e o Desenvolvimento Orientado pelo Transporte ganharam popularidade nos últimos anos (CNU, 2019; Lamour, Morelli e Marins, 2019). Partindo do pressuposto de que o ambiente construído pode desempenhar um papel importante para apoiar comportamentos sociais e saudáveis (Hino, Reis e Florindo, 2010; Dean et al., 2020), essas estratégias buscam reduzir viagens motorizadas, aumentar a participação do deslocamento ativo e criar bairros mais caminháveis.

A caminhada é um modo de transporte socialmente equitativo e economicamente viável, a qual pode ser realizada por diversas faixas etárias e perfis populacionais (Lee e Moudon, 2006; Nakamura et al., 2014). Além de reduzir congestionamentos e ter menor impacto ambiental, convida também as pessoas ao espaço público (Southworth, 2005; Sallis e Glanz, 2009).

Sabe-se que a caminhada pode ser influenciada por diversos fatores e domínios que incluem variáveis interpessoais, ambientais e políticas (Sugiyama et al., 2012). Assim, o padrão de viagem da população está se tornando cada vez mais complexo e, portanto, as características do ambiente construído em torno de diversos pontos de origem com diferentes usos podem ser tão importantes para explicar o comportamento de viagem e a escolha modal (Vale, Saraiva e Pereira, 2016). Neste sentido, os modelos ecológicos relacionam características ambientais e sociais determinantes para a atividade física, como condições econômicas, padrões sociais, urbanização e industrialização (Bauman et al., 2012).

Por outro lado, pesquisas apontam que não somente a origem, mas também estudar os propósitos do deslocamento, o porquê, permite examinar a escolha do modo de transporte como parte de um comportamento contínuo, e não apenas como uma atividade isolada (Perchoux et al., 2019). Os propósitos distintos estão associados a diferentes características do ambiente construído, como distância e tempo decorrido para a caminhada (Lee e Moudon, 2006; Yang e Diez-Roux, 2012).

A pesquisa de Yang e Diez-Roux (2012) demonstrou que existe variabilidade substancial nas distâncias e durações de viagens a pé para diferentes propósitos. De acordo com Agrawal, Schlossberg e Irvin (2008), a distância da viagem é o fator que mais influencia a caminhada. Assim, entende-se que distâncias associadas a características espaciais do ambiente construído refletem um fator importante para o estudo da caminhada.

Neste sentido, oferecer uma variedade de destinos próximos a áreas residenciais, por meio da mistura de usos, pode ser uma maneira de incentivar o deslocamento ativo por encurtar a distância entre a origem e o destino das viagens (Song, Merlin e Rodriguez, 2013; Tian e Ewing, 2017). Por isso, além de entender o motivo do deslocamento, é importante analisar se existem destinos para onde as pessoas podem ir dentro de uma distância caminhável.

Considerando o tempo e a distância, ainda existe um questionamento sobre os propósitos que poderiam ser considerados para o deslocamento a pé. Nesse sentido, a partir de uma busca exploratória da literatura, foram selecionados 12 artigos científicos publicados nos últimos 20 anos, tendo a caminhada como tema de pesquisa e que apresentassem uma classificação de propósitos (Krizek, 2003; Yang e Diez-Roux, 2012; Millward et al., 2013; Hatamzadeh et al., 2014; Scheepers et al., 2014; Larranaga e Cybis, 2014; Mirzaei et al., 2018; Mondschein, 2018; Perchoux et al., 2019; Yang et al., 2019; Fonseca et al., 2021).

Observou-se uma grande divergência entre as classificações, que variam de acordo com os objetivos de cada estudo e da disponibilidade de dados. Aqueles dados provenientes de GPS forneceram categorias específicas (Millward et al., 2013); por outro lado, outras pesquisas apresentaram uma generalização de categorias (Hatamzadeh et al., 2014; Scheepers et al., 2014; Larranaga e Cybis, 2014; Mirzaei et al., 2018, Fonseca et al., 2021, Krizek, 2003; Yang e Diez-Roux, 2012; Mondschein, 2018; Perchoux et al., 2019), aplicável ao nível de refinamento dos dados disponíveis.

A pesquisa de Yang et al. (2019) definiu categorias a partir da identificação de Pontos de 
Interesse". Com base no número de POIs encontrados, as viagens foram rotuladas em 221 categorias, que foram reclassificadas em seis tipos de uso do solo, levantados através dos dados dos propósitos de destinos das viagens: comercial, lazer, residencial, trabalho, educação e outros. Os autores examinaram também as variações temporais do deslocamento e os objetivos das viagens.

Um outro olhar de categorização parte dos deslocamentos para onde indivíduos "moram", "trabalham" ou "visitam" com base nas funções principais desenvolvidas no espaço urbano (Dovey e Pafka, 2017). Apesar de focar na mistura dos usos, este trabalho se torna importante como classificação de propósitos em busca dos motivos "funcionais" do deslocamento do pedestre para diferentes partes da cidade.

Portanto, o foco deste estudo é contribuir com o entendimento sobre a relação entre o ambiente construído e a intenção pela qual as pessoas escolhem o deslocamento a pé. Afinal, os propósitos apresentam diferentes restrições de tempo e espaço (Fonseca et al., 2021), os quais devem ser vistos como fator importante para o entendimento do fenômeno complexo da caminhada.

No Brasil, diversos estudos têm aplicado diferentes metodologias para explorar as associações entre variáveis do ambiente construído com a caminhabilidade, na micro (Lopes et al., 2018; Cambra e Moura, 2020) ou macroescala, abrangendo os índices de caminhabilidade (Motomura, Fontoura e Kanashiro, 2018; Leão et al., 2020). Entretanto, poucas com foco nos propósitos de caminhada. Portanto, entender o que constitui uma distância caminhável para cada propósito pode contribuir para que diretrizes de planejamento urbano deem suporte ao deslocamento ativo (Gunn et al., 2017; Yang e Diez-Roux, 2012).

É demonstrado também que, quanto menor o porte do município, maior é o deslocamento por transporte não motorizado e menor o uso do transporte coletivo (CNI-Ibope, 2015), o que aponta para a necessidade de avaliações para subsidiar políticas de mobilidade ativa em cidades médias e pequenas, como o estudo recente de Guimarães et al. (2019). Implementar e projetar zonas urbanas que estimulem viagens ativas está associado a impactos positivos nas cidades e, portanto, nas pessoas (Guzman, Peña e Carrasco, 2020).

Assim, o problema de pesquisa investigado é a influência dos diferentes propósitos de caminhada nas distâncias percorridas a pé. A pesquisa tem como objetivo geral analisar as rotas caminhadas por diferentes propósitos em uma cidade média brasileira, a partir dos dados de distância, duração e uso do solo do entorno das rotas. Portanto, pretende-se: (1) identificar os diferentes propósitos de caminhada; (2) calcular as respectivas distâncias e durações médias de caminhada por propósitos e (3) analisar o uso do solo do entorno das rotas por propósito.

\section{Método}

Como estratégia metodológica, estabeleceu-se o estudo de caso, recomendado em investigações de contexto real e determinante para a ocorrência do fenômeno (Yin, 2001), realizado na cidade de Cambé-PR (Figura 1). O município está inserido na Região Metropolitana de Londrina, localizada no norte do estado do Paraná, possui 495,375 km² de área territorial e população estimada 107.341 habitantes (IBGE, 2020), sendo, portanto, uma cidade de porte médio (entre $100 \mathrm{mil} \mathrm{e} 500 \mathrm{mil}$ habitantes). Por isso, Cambé é considerada representativa das cidades médias brasileiras, e sua escolha como estudo de caso também é justificada pela disponibilidade dos dados de uso do solo no nível do lote, coletados pelo Grupo de Pesquisa (GP) Design Ambiental Urbano/UEL, e dados de caminhada do Plano de Mobilidade, coletados pelo ITEDES (Instituto de Tecnologia e Desenvolvimento Econômico e Social). 


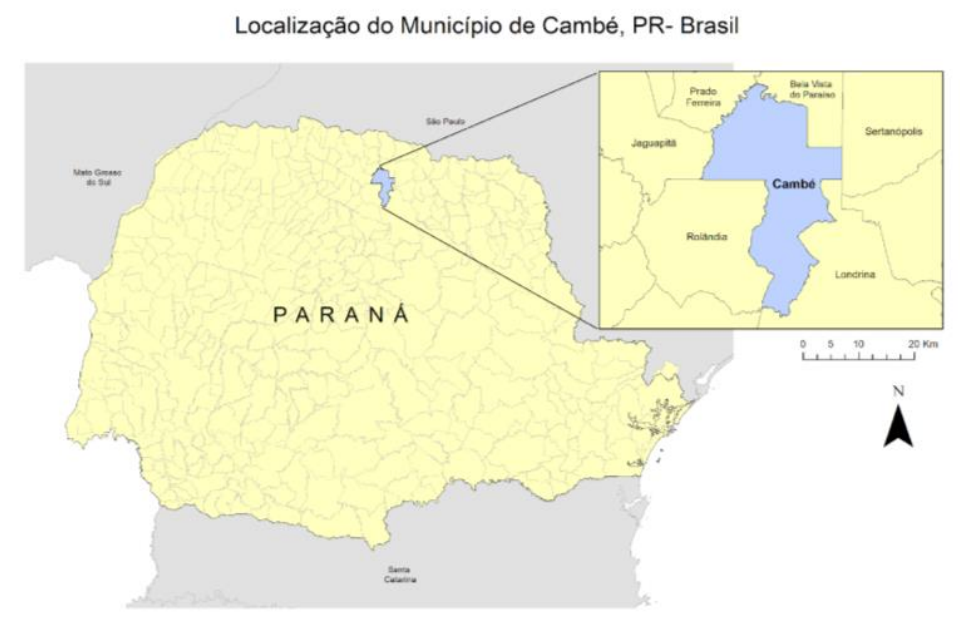

Figura 1. Localização do município de Cambé (fonte: IBGE, 2010, elaborado pelas autoras, 2021).

A generalização do estudo de caso não é direta, mas existe em função da representatividade da análise dentro dos resultados alcançados. Ademais, entende-se também a importância de pesquisas contextualmente relevantes para a tomada de decisão, com dados locais (Sallis et al., 2016). Apesar de existirem diversas ferramentas e índices para a avaliação da caminhabilidade, a abordagem deste estudo se estrutura em uma análise quantitativa e espacial que foi delimitada a partir de uma base de dados disponível como indicado por vários outros estudos da área (Motomura et al., 2018; Guimarães et al., 2019; Leão et al., 2020).

Categorias: motivos, pontos de interesse e funções.

A partir das discussões teóricas, propõe-se uma investigação em três categorias: motivos, pontos de interesse e funções. A diferença entre as classificações relaciona-se aos níveis de agregação dos dados, portanto, podem variar na chamada "escala de propósitos", da mais específica até a mais simplificada.

A categoria de Motivos segue a nomenclatura presente na base de dados, proveniente do questionário da pesquisa de Origem-Destino (OD) em que os respondentes marcavam o motivo do deslocamento, com base no uso do destino. Os motivos são organizados em 9 categorias: trabalho/indústria, trabalho/comércio, trabalho/serviço, educação, compras, saúde, lazer, residência e outros.

As categorias de "Pontos de Interesse" apresentam pouca variação em relação aos Motivos de deslocamento listados na base de dados fornecida pelo ITEDES (2017). Os POIs são organizados em 6 categorias: comercial, lazer, residencial, trabalho, educação e outros.

Já a categoria de Funções, também representa o objetivo para o qual o pedestre se deslocou, mas com foco nas atividades funcionais do deslocamento, na ação do pedestre, com base nas classificações de pesquisas da área. As funções são organizadas em 3 categorias: trabalhar/estudar, visitar e morar. Adicionou-se a classe "outros" pela necessidade de realocar dados da base de motivos que não integravam outra categoria existente.

Para análise do uso do solo, foi utilizada a classificação usada por Frank et al. (2010) no artigo em que é apresentado o índice de caminhabilidade, estratégia amplamente aplicada nas pesquisas sobre caminhabilidade dos últimos anos. Neste índice, os usos são classificados em: residencial, comercial, serviço, institucional e entretenimento. Nos lotes em que há mais de um uso, foram adotadas duas estratégias: a primeira, quando um dos usos presentes era o residencial, aplicou-se a categoria "uso misto"; e, segundo, quando os usos eram não-residenciais, os lotes foram subdivididos na base e reclassificados. Os lotes sem ocupação ou em construção foram classificados como "vazio". Pré-processamento de dados

A partir dos dados da pesquisa OD de Cambé, a base dos dados indica o motivo de deslocamento. Foram aplicados 1.302 questionários, entre novembro/2015 a abril/2016, totalizando 4,7\% do total de 27.667 Domicílios Particulares Permanentes (ITEDES, 2017). Um adulto responsável pela casa respondeu a um questionário que identificou os deslocamentos, relaci- 
onando pontos de destino, modos de transporte, tempo e motivo. Os dados de deslocamentos realizados por todos os modais da pesquisa OD (ITEDES, 2017) são compostos por
4.699 viagens. Destas, foram selecionadas 1.125 que correspondem ao modo "a pé" e distribuídas nos seguintes motivos (Gráfico $1)$ :

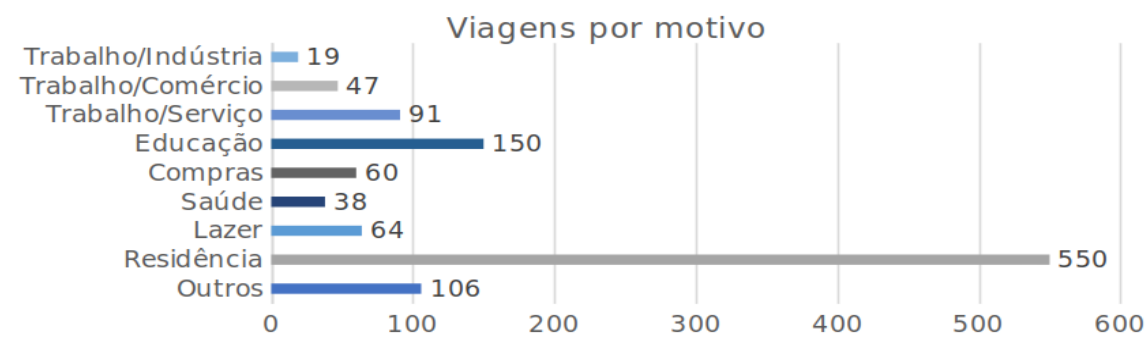

Gráfico 1. Quantidade de viagens por motivo (fonte: ITEDES, 2017; organizado pelas autoras, 2020).

Para o georreferenciamento das rotas, foram descartadas 45 viagens que apresentavam informações de endereço incompletas. Assim, o número final de viagens a pé corresponde à amostra de $n=1.080$.

\section{Georreferenciamento das rotas}

Os dados foram espacializados em Sistema de Informações Geográficas (SIG) pelo Grupo de Pesquisa Design Ambiental Urbano, os quais seguem o referencial geodésico SIRGAS2000 (Sistema de Referência Geocêntrico para as Américas) e projeção UTM zone 22S. As origens e destinos das 1.080 viagens foram sistematizados e georreferenciados pela aplicação ArcGIS 10.6 Online através de um mapa base disponibilizado pela Prefeitura do Município de Cambé (PMC) (2020). Os pontos de origem e destino foram conectados e as rotas criadas a partir do caminho mais curto entre os dois pontos, considerando a malha viária e um deslocamento a pé.

É importante ressaltar que as rotas foram geradas automaticamente pelo ArcGIS com base nas informações de endereço de origem e destino fornecidas, por isso são estimativas computadorizadas. Ademais, para analisar o tempo de duração das viagens, foram utilizadas as informações autorreportadas nos questionários, e não o tempo de viagem vinculado às rotas georreferenciadas. Sabe-se que dados de distância e tempo de viagens podem ser superestimados em autorrelatos (Dewulf et al., 2012) e que o arredondamento pode resultar em medidas adicionais imprecisas (Yang et al.
2012). Entretanto, tal estratégia foi definida para que fosse possível comparar os resultados de distância e tempo sem que fossem dados análogos, ou seja, o mesmo dado transformado. Ainda, esta escolha metodológica foi adotada em uma tentativa de captar a percepção do pedestre sobre a viagem na análise, visto que a maneira com a qual os atributos ambientais são apreendidos interfere diretamente no que é percebido durante a caminhada (Guimarães et al., 2019).

\section{Classificação e processamento dos dados}

Para o cálculo das médias por propósitos, exportou-se a tabela gerada no ArcGIS para o programa Excel. Os motivos de viagem (ITEDES, 2017) foram reclassificados nas duas outras escalas de propósitos definidas na revisão de literatura: por pontos de interesse (Yang et al., 2019) e por funções (Dovey e Pafka, 2017) seguindo a seguinte estratégia (Figura 2). A classe referente à "residência", ou "morar", englobou as mesmas categorias definidas nos dados base de OD nas três classificações (Motivos, POIs e Funções), pois apesar de possuírem os mesmos valores dentro de categorias diferentes, não poderiam ser inseridas dentro de outras classes, mas ainda eram de grande importância de análise dentro de cada escala. A classe "outros", abrigou dados que não se agruparam nas demais categorias. 


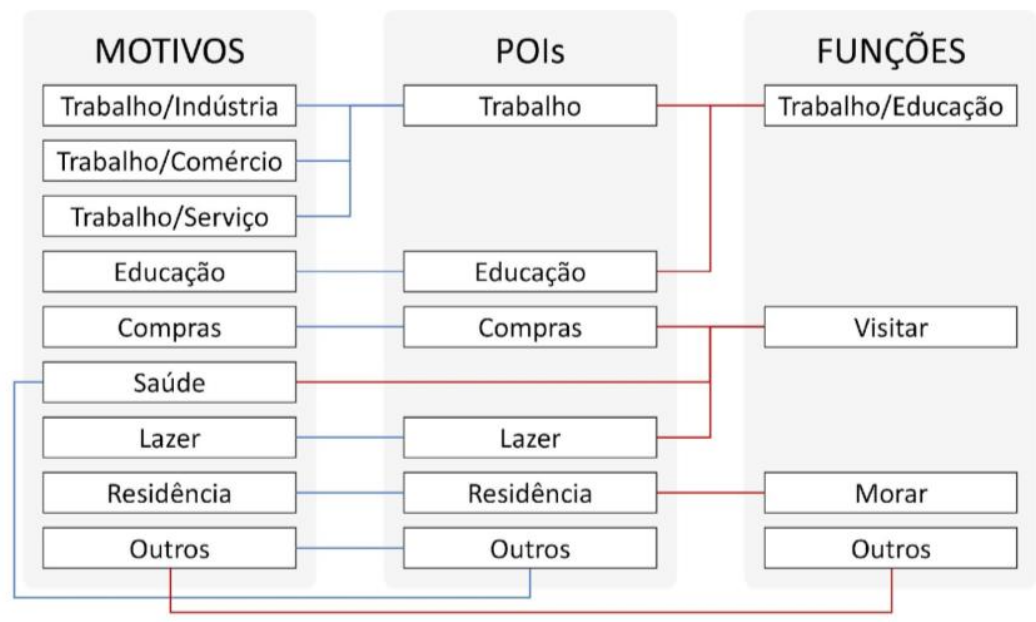

Figura 2. Reclassificação dos motivos em propósitos (fonte: elaborado pelas autoras, 2020).

A partir disso, desenvolveram-se análises quantitativas na ferramenta Excel, onde os dados foram organizados em tabelas para interpretação de cada categoria de propósito e suas médias. Foram então gerados gráficos de função de decaimento para os propósitos de caminhada, de acordo com a categoria função, por meio da agregação das rotas em porcentagem cumulativa, a fim de tornar essas frequências brutas em gradientes comparáveis. $\mathrm{O}$ elemento-chave das funções é um parâmetro que descreve o alcance espacial das viagens para um propósito, esse parâmetro geralmente é interpretado em termos da disposição dos viajantes em percorrer determinada distância (Iacono, Krizek e El-Geneidy, 2008). Buscase entender melhor sobre até onde e por quanto tempo as pessoas se deslocam a pé para alcançar certos destinos, e se existem diferenças potencialmente significativas entre eles.

Os valores de distância foram estabelecidos em intervalos de $400 \mathrm{~m}$, e os de duração a cada 5 minutos, identificados por apresentarem as maiores variações percebidas nos dados fornecidos pelo ITEDES (2017), e com base nas evidências de que a caminhada média para $400 \mathrm{~m}$ dura cerca de 5 minutos (Gunn et al., 2017; Iacono, Krizek e El-Geneidy, 2008). Além disso, como buscou-se analisar o comportamento de decaimento da tendência da caminhada versus o aumento da duração e da distância, rotas inferiores a esses valores não foram consideradas no gráfico por se apresentarem como a configuração mínima aceitável de caminhada (Hatamzadeh, Habibian e Khodaii, 2014; Yang e Diez-Roux, 2012).

\section{Seleção das rotas e análise espacial}

Para melhor compreensão da relação do ambiente construído com o comportamento de caminhada por diferentes propósitos, foi realizada uma análise espacial no entorno de rotaspadrão de cada propósito as quais foram escolhidas de acordo com cada Função classificada em Dovey e Pafka (2017). Essa categorização, assim como na geração dos gráficos, foi utilizada para captar também, além dos destinos, a influência das funções urbanas no ato de caminhada.

Para a definição das rotas-padrão por Função, ou seja, uma rota representativa, foram adotados dois critérios: ter o valor de distância próximo da média encontrada na Função, considerando o intervalo de confiança das médias, e passar pelas vias mais carregadas de viagens a pé. Calcularam-se intervalos de confiança para as médias encontradas e, em seguida, rotas com valores de distância inseridas nesse intervalo foram localizadas espacialmente no ArcGIS para confrontar com os valores de carregamento viário, e assim selecionadas.

A rota selecionada foi sobreposta no mapa de carregamento e uma análise do uso do solo no entorno imediato foi realizada a partir de um banco de dados de uso do solo levantado manualmente pelo GP de Design Ambiental Urbano/UEL. O mapa de carregamentos corresponde à quantidade de vezes que viagens reportadas na pesquisa OD passaram pela via, ou seja, quanto mais viagens passam na mesma via, maior é o seu carregamento e, assim, é possível identificar as concentrações de vias caminhadas na malha urbana. 
Definidas e localizadas as rotas-padrão, foram sistematizados os dados de uso do solo dos lotes adjacentes à via, com o objetivo de analisar quais atividades estão localizadas ao longo do percurso. Essa análise visa a identificar possíveis destinos atrativos para os pedestres de acordo com o propósito, a partir das atividades presentes no entorno imediato, ou percurso daquela rota. Afinal, a diversidade de usos do solo reflete a disponibilidade de destinos para onde os moradores podem caminhar na escala do bairro (Duncan et al., 2010).

\section{Resultados e análises}

Os resultados apresentam-se em duas etapas: apresentação do conjunto de dados finais das médias de distância e duração das viagens a pé; e a espacialização das rotas-padrão de cada propósito.

\section{Análise quantitativa}

Na primeira abordagem, realizou-se a análise por meio das classificações propostas (motivo, POIs e funções) em uma visão abrangente do comportamento da viagem e propósitos de caminhada. Os dados de distância (Tabela 1) de cada viagem foram processados de acordo com cada escala de propósitos e as médias foram identificadas.

\begin{tabular}{lccccc}
\hline \multicolumn{1}{c}{ Motivos } & $\begin{array}{c}\text { Dist. } \\
\text { média }\end{array}$ & POIs & $\begin{array}{c}\text { Dist. } \\
\text { média }\end{array}$ & Funções & Dist. média \\
\hline Trabalho/indústria & $2,493^{* *}$ & Trabalho & $1,830^{* *}$ & Trabalhar/estudar & 1,487 \\
Trabalho/comércio & 1,780 & & - & & - \\
Trabalho/serviço & 1,712 & & - & & - \\
Educação & 1,133 & Educação & 1,133 & & - \\
Compras & 1,119 & Comercial & $1,119^{*}$ & Visitar & $1,173^{*}$ \\
Saúde & $0,844^{*}$ & & - & & - \\
Lazer & 1,420 & Lazer & 1,420 & & - \\
Residência & 1,588 & Residencial & 1,588 & Morar & $1,588^{* *}$ \\
Outros & 1,178 & Outros & $1,011^{*}$ & Outros & 1,178 \\
\hline Média Total=1,463 & \multicolumn{5}{c}{} \\
Obs.: $\left({ }^{*}\right)$ Menor média, $(* *)$ Maior média
\end{tabular}

Tabela 1. Distâncias médias percorridas por escalas de propósito (em quilômetros) (fonte dos dados: ITEDES, 2017. Elaborada pelas autoras, 2020).

A distância média variou de maneira considerável entre os diferentes propósitos, sendo a média total de todas as viagens de $1,463 \mathrm{~km}$. Quando analisada por POIs, obteve-se maior distância para "trabalho" $(1,830 \mathrm{~km})$ e menor para "comercial" (1,119 km). Por Função, os respondentes andam mais para "morar" $(1,588$ $\mathrm{km})$ e menos para o "visitar" (1,173 km).

A maior distância em "trabalho" (POIs) pode ser explicada por abranger atividades diárias indispensáveis, e pelo fato de que as principais áreas de emprego tenderem a ser mais separadas das áreas residenciais (Millward, Spinney e Scott, 2013). Este resultado se assemelha às evidências obtidas por Larsen et al. (2010), as quais identificaram no propósito do trabalho as maiores distâncias médias. Por outro lado, a maior média em "morar" (Funções) pode estar relacionada ao fato de usos residen- ciais não precisarem seguir uma lógica espacial, sendo distribuídos por toda cidade e, assim, possuir distâncias variadas de acesso a diversos usos urbanos. Ademais, a maioria das viagens têm a residência como origem ou destino (Krizek, 2003). Portanto, nessas áreas residenciais, episódios de viagens para ou de casa são mais longos que a média, refletindo a falta de oportunidades de destino, principalmente para compras dentro dos bairros (Millward, Spinney e Scott, 2013).

A divergência de resultados entre as categorizações pode ser entendida pela diferente forma de agrupamento dos dados. Quando analisados por Funções, o agrupamento dos três motivos de "trabalho" que apresentam certa variação e maiores valores, junto aos dados de "educação" os quais possuem valores um pouco menores, geram uma média menor na categoria "trabalhar/estudar". Entretanto, 
essas categorizações ainda se configuram como atividades mandatórias ou frequentes (Millward, Spinney e Scott, 2013), justificando seu agrupamento em uma mesma categoria. Os valores mais altos na categoria "trabalhar" (POIs) originam-se do motivo "trabalho/indústria", o qual possui valores significativamente maiores, possivelmente decorrentes das localizações mais periféricas e distantes das áreas industriais em Cambé.

Ambas as escalas apresentaram a menor distância em classes correspondentes de propósitos, em "comercial" (POIs) e "visitar" (Funções). Entende-se que para compras diárias, indivíduos geralmente não se destinam às compras longe da residência de origem, principalmente quando precisam carregar mantimentos. Nestes casos, distâncias maiores significam mais esforço físico, tornando a caminhada menos tendenciosa a ser realizada a pé a medida que a distância aumenta (Gim,
2011). Essa concordância entre as categorias pode ser entendida pela forma similar de agrupamento dos dados a partir da base de motivos. Em "visitar", percebe-se que todas as categorias provenientes dos motivos apresentam características semelhantes de distâncias não tão altas. Por exemplo, "saúde", estaria associada à baixa probabilidade de caminhar até os locais de consultas médicas, por ter a peculiaridade de envolver o mal-estar do paciente, ainda mais com o aumento da distância. E como uma classificação de motivos de "lazer" se exprime pela relativa restrição na seleção de opções de atividades e pela variação das opções de destino as quais cada região oferece (Gim, 2011), a distância encontrada apresenta-se nem tão alta, nem tão baixa, dada a variação de valores das rotas. Isso contribui para um resultado de menores médias finais.

Da mesma forma, dados de tempo de viagem foram processados (Tabela 2):

\begin{tabular}{lccccc}
\hline Motivos & Dur. média & POIs & Dur. média & Funções & Dur. média \\
\hline Trabalho/indústria & $20,53^{* *}$ & Trabalho & 17,04 & Trabalhar/estudar & $16,02^{*}$ \\
Trabalho/comércio & 15,89 & & - & & - \\
Trabalho/serviço & 16,88 & & - & & - \\
Educação & $14,96^{*}$ & Educação & $14,96^{*}$ & & - \\
Compras & 15,35 & Comercial & 15,35 & Visitar & $16,46^{* *}$ \\
Saúde & 15,17 & - & - & & - \\
Lazer & 18,32 & Lazer & $18,32^{* *}$ & & - \\
Residência & 16,39 & Residencial & 16,39 & Morar & 16,39 \\
Outros & 15,30 & Outros & 15,27 & Outros & 15,30 \\
\hline Média total=16,20 & \multicolumn{5}{c}{} \\
\hline Obs:(*) Menor média, $(* *)$ Maior média
\end{tabular}

Tabela 2. Duração média percebida por escala de propósito (em minutos) (fonte dos dados: ITEDES (2017). Elaborada pelas autoras, 2020).

As médias autorreportadas de tempo de deslocamento apresentaram variações mínimas em relação à média geral de todas as viagens (Média=16,20). Os resultados mostram que, na categorização por POIs, a maior média encontrada foi em "lazer", e a menor, em "educação". Por outro lado, na categorização por Funções, o maior valor encontrado foi em "visitar", e o menor, em "trabalhar/estudar". A categoria "outros" foi desconsiderada na análise, pois visou-se a entender os dados relacionados com os propósitos de caminhada e nesta categoria não seria possível identificá-los.

Tanto "lazer" (POIs) quanto "visitar" (Funções) apresentam as maiores durações percebidas. Esse resultado reflete a natureza mais arbitrária e aprazível das viagens de entretenimento ou recreação e a falta de restrições estritas de tempo no decorrer do cronograma diário de atividades do indivíduo (Iacono, Krizek e El-Geneidy, 2008, Mirzaei et al., 2018, Yang e Diez-Roux, 2012). Além disso, são mais possíveis de serem realizadas para além do bairro de origem, demandando mais tempo (Krizek, 2003). Assim como já observado na análise das distâncias, os resultados correspondentes podem ser explicados pelo agrupamento similar dos dados base.

Já as menores durações médias encontraramse em "educação" (POIs) e "trabalhar/estudar" (Funções). Esse resultado diverge das evidências apresentadas por Iacono et al. (2008), as 
quais encontraram menores valores para compras e restaurantes. Isto pode estar relacionado ao fator geográfico e sociodemográfico da área que está sujeita à base de dados, ou seja, são áreas geográficas de análise diferentes com uma população inserida em outro aspecto socioeconômico. Acredita-se que o menor tempo encontrado desde a base de dados dos motivos em "educação", categorizada nos POIs de "educação" e na função de "trabalhar/estudar", possa estar relacionado às restrições de horários, tanto das aulas quanto do trabalho. No caso do trabalho, apesar de o motivo "trabalho/indústria" possuir valores maiores que os demais, encontra-se relacionado à natureza de tempo limitado (Krizek, 2003).

Novamente, nota-se a diferença de resultados entre as categorizações. Quando analisados por POIs, obtém-se uma visão mais detalhada de cada propósito. Por outro lado, na análise por Funções, entende-se as distâncias e durações das rotas caminhadas de maneira mais ampla e com foco na compreensão do comportamento dos indivíduos de acordo com as funções principais de deslocamento na cidade. Quando agrupadas nessa escala, permite-se direcionar a atenção para resultados que levantem os propósitos de caminhada focado nessas atividades principais, e não somente no uso do destino.

Portanto, uma segunda abordagem analítica foi desenvolvida a partir dos resultados da categoria Funções, buscando uma compreensão mais aprofundada e objetiva na relação entre a distância e a duração da viagem e como isso afeta o deslocamento por propósitos (Gráficos 2 e 3 ).

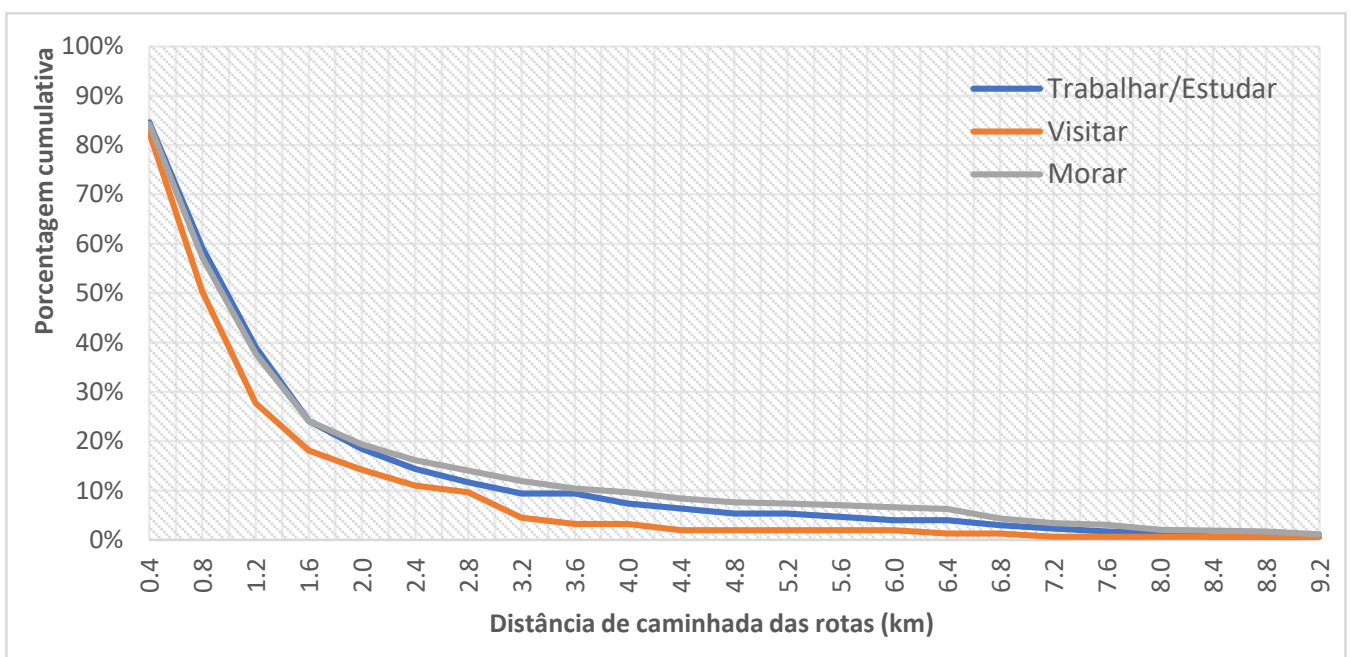

Gráfico 2. Curva de decaimento de distâncias percorridas por funções (fonte: elaborado pelas autoras, 2020).

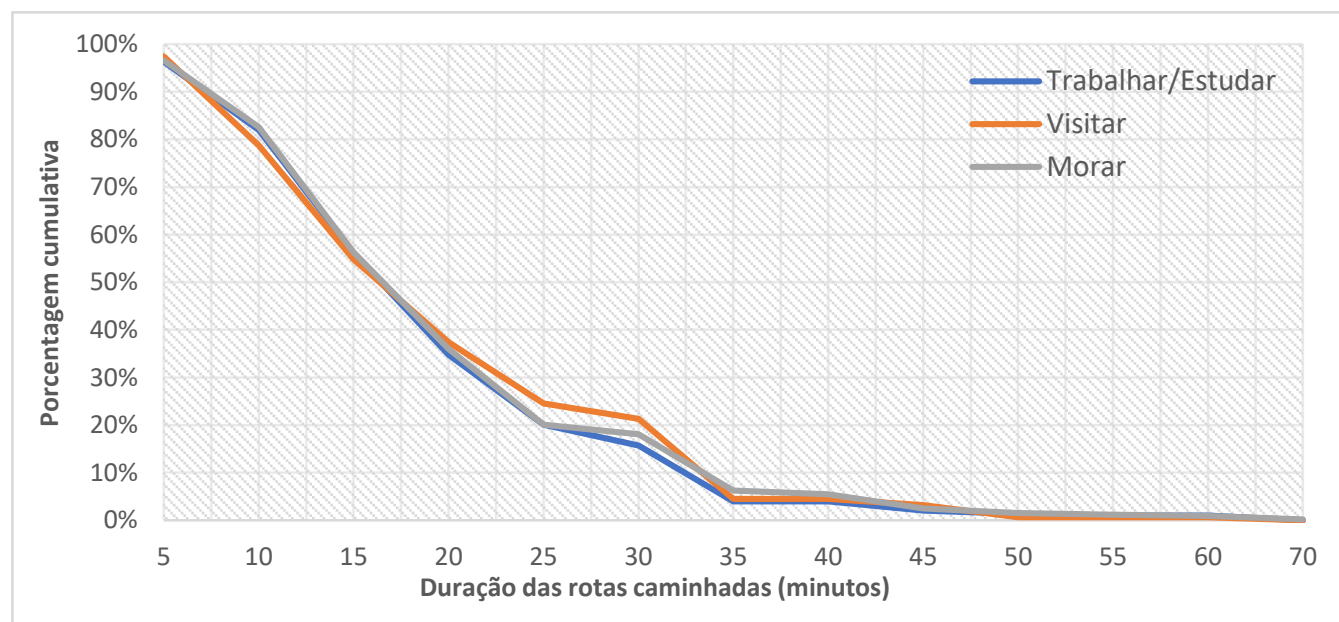

Gráfico 3. Curva de decaimento de durações percebidas por funções (fonte: elaborado pelas autoras, 2020). 
Mais da metade de todas as viagens a pé são realizadas até 800 metros (50\% para "visitar" e 57\% para "trabalhar/estudar" e "morar") e duram até 15 minutos (cerca de $56 \%$ nos três propósitos). Menos de um quinto das rotas apresentou mais de 2,0 km e ultrapassou 30 minutos. Apesar de possuírem valores diferentes quando desagregadas por propósito, as linhas de decaimento apresentam comportamentos similares. No gráfico 2 , verifica-se que até cerca de $1,6 \mathrm{~km}$ a linha de decaimento sofre uma queda mais rígida, e em seguida apresenta uma tendência moderada. Isso pode ser explicado pela propensão da influência das distâncias mais curtas na escolha de caminhada (Scheepers et al., 2014). No gráfico 3, a linha de decaimento mantém-se até 25 minutos e, posteriormente, entre os intervalos de 25 a 30 e 30 a 35 , acentua de maneira mais contínua. De 35 minutos em diante, o decaimento apresentou variações muito pouco significativas, o que pode indicar que uma caminhada de duração maior que 30 minutos apresenta uma menor tendência dos indivíduos.

Tanto "trabalhar/estudar", quanto "morar", apresentaram resultados similares, possivelmente por se comportarem como funções mandatórias (Larranaga e Cybis, 2014). Já a função "visitar", apresenta valores que sofrem maior variação e maior queda da curva das viagens, na relação de tendência de caminhar versus o aumento da distância. Este resultado provavelmente é encontrado por ser uma atividade de tempo-livre, ou seja, não acompanha padrões de caminhada e realiza-se em horários mais flexíveis (Perchoux et al., 2019).

\section{Análise espacial}

Ao encontrar variações dos resultados das distâncias médias na categoria de Funções, o entorno das rotas foi analisado a fim de entender a relação entre o ambiente construído e os propósitos de caminhada. Afinal, é preciso entender até que ponto as pessoas escolherão caminhar como meio de transporte e os fatores ambientais que as influenciam (Agrawal, Schlossberg e Irvin, 2008; Iacono, Krizek e El-Geneidy, 2008).

$\mathrm{Na}$ Tabela 3, apresentam-se os valores do intervalo de confiança de $95 \%$, definidos a partir das distâncias médias encontradas na Tabela 1, utilizadas para determinar a escolha das rotas-padrão.

\begin{tabular}{lllll}
\hline Função & IC 95\% (inferior) & Média & IC 95\% (superior) & Rota-padrão $(\mathrm{km})$ \\
\hline Trabalhar/Estudar & 1.2983 & 1.4871 & 1.6759 & 1.5128 \\
Visitar & 0.9766 & 1.1733 & 1.3700 & 1.1084 \\
Morar & 1.4256 & 1.5882 & 1.7508 & 1.7160 \\
\hline
\end{tabular}

Tabela 3. Intervalos de confiança (IC) e rota escolhida (fonte: elaborada pelas autoras, 2020).

O processo urbano atuou como um fio condutor da discussão aqui empreendida sobre estudos morfológicos potencializados pela cartografia digital, particularmente em Nos mapas de carregamento viário, em que são localizadas as rotas-padrão selecionadas nesta pesquisa, foram sobrepostos os núcleos urbanos identificados na pesquisa de Motomura et al. (2018), cujo estudo histórico e evidências locais foram desenvolvidos considerando as proposições de Silveira (1989), para complementar a análise espacial das rotas.

No mapa de carregamento viário "trabalhar/estudar" (Figura 3), percebe-se que as principais concentrações de viagens localizam-se: no núcleo original, onde há predominância de varejo e serviços e, portanto, consti- tui o principal local de intercâmbio econômico; em parte da BR-369 que dá acesso à cidade de Rolândia; e acontecem duas outras concentrações em menor grau em regiões mais afastadas da região central, em que ambas são cortadas por vias de acessos principais de deslocamento para além do bairro.

No mapa de usos da rota "trabalhar/estudar" $(1,48 \mathrm{~km})$ (Figura 3$)$, que possui uma localização urbana mais central, existe pouca presença de vazios com predominância de uso residencial, principalmente na área próxima à sua origem. Nota-se também a presença de um fundo de vale próximo à origem da rota, o qual delimita a malha urbana e define sua ocupação. Na predominância residencial destaca-se um grande lote de entretenimento, onde localiza- 
se um campo de esportes que pode ser acessado pelos moradores. Conforme a rota se aproxima da ferrovia, aumenta a incidência de usos não-residenciais. Para fazer a transposição da linha férrea, a rota sofre um desvio, provavelmente passando por um caminho de pedestres existente. A ferrovia é um elemento estruturador da malha urbana de Cambé, presente desde a implementação da cidade pela
Companhia de Terras do Norte do Paraná (CTNP), em 1932. As ferrovias tiveram um papel importante no início da colonização da região, eram um dos símbolos de um Norte do Paraná efervescente (Yamaki, 2017) e delinearam o posicionamento dos núcleos urbanos e coloniais (Rego e Meneguetti, 2008).

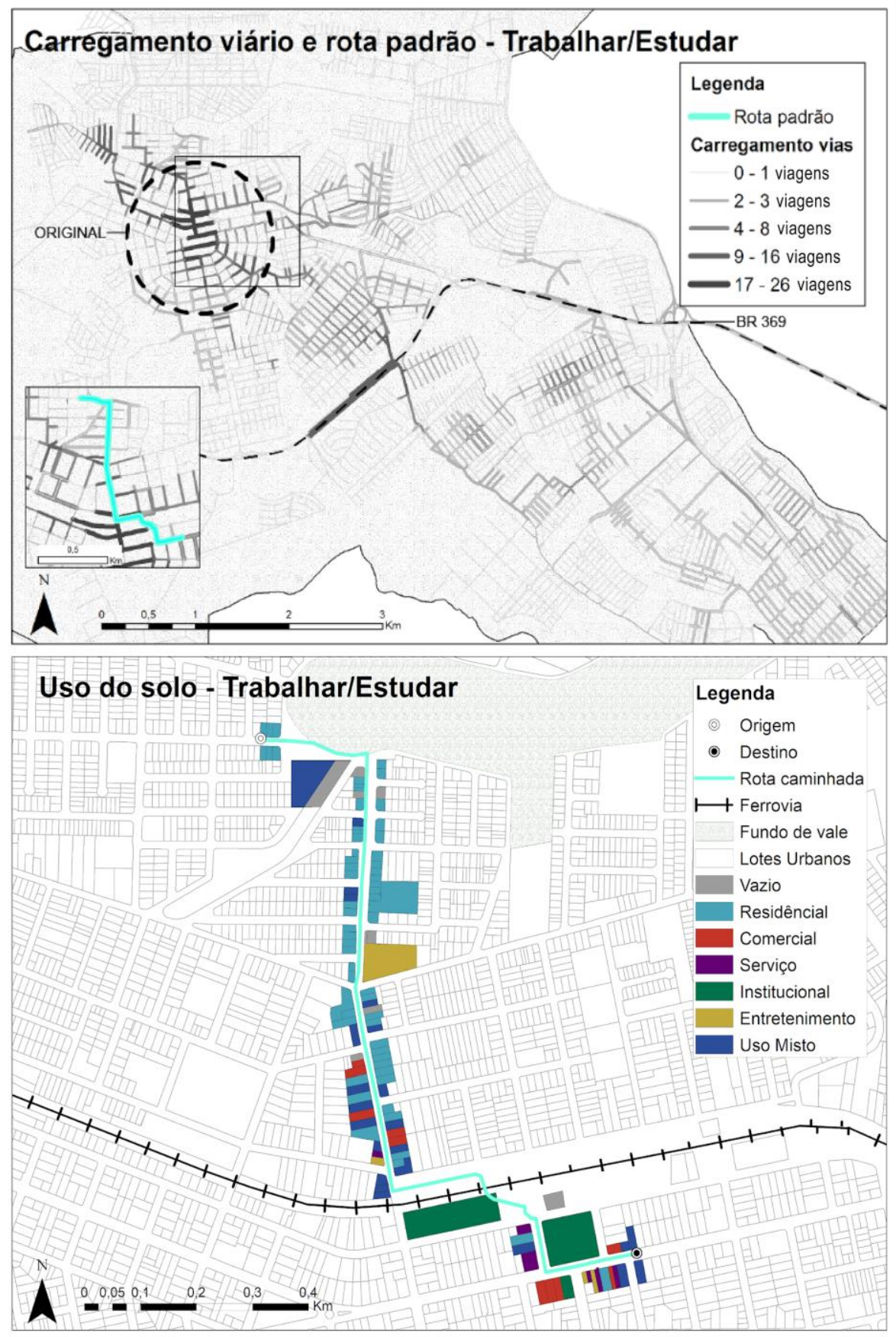

Figura 3. Mapas do propósito "trabalhar/estudar": carregamento viário e localização da rota-padrão (acima) e uso do solo (abaixo) (fonte: PMC, 2020, GP Design Ambiental Urbano, 2020, ITEDES, 2017, sistematizado pelas autoras, 2021). 
Próximo ao destino, no entorno da linha férrea e centro-histórico da cidade, localizam-se lotes institucionais de maiores proporções, bem como lotes comerciais e de serviços. De acordo com o questionário da pesquisa $\mathrm{OD}$, o indivíduo informou que sai do motivo de "residência" e se desloca a pé para "trabalho" porque as outras opções de deslocamento são mais demoradas. Assim, a caminhada é, possivelmente, a opção mais acessível de transporte ao destino de trabalho.
Na Figura 4, identificam-se três áreas de maior concentração do carregamento viário para "visitar": na região central da cidade, que apresenta diferentes tipos de usos; no núcleo Ana Rosa e no Industrial, que foram consequências de projetos para atender à demanda habitacional da classe trabalhadora e resultou em arranjos de pequenos lotes, que, de acordo com as regulamentações brasileiras, fortaleceram a formação de distritos densos (Motomura et al., 2018).
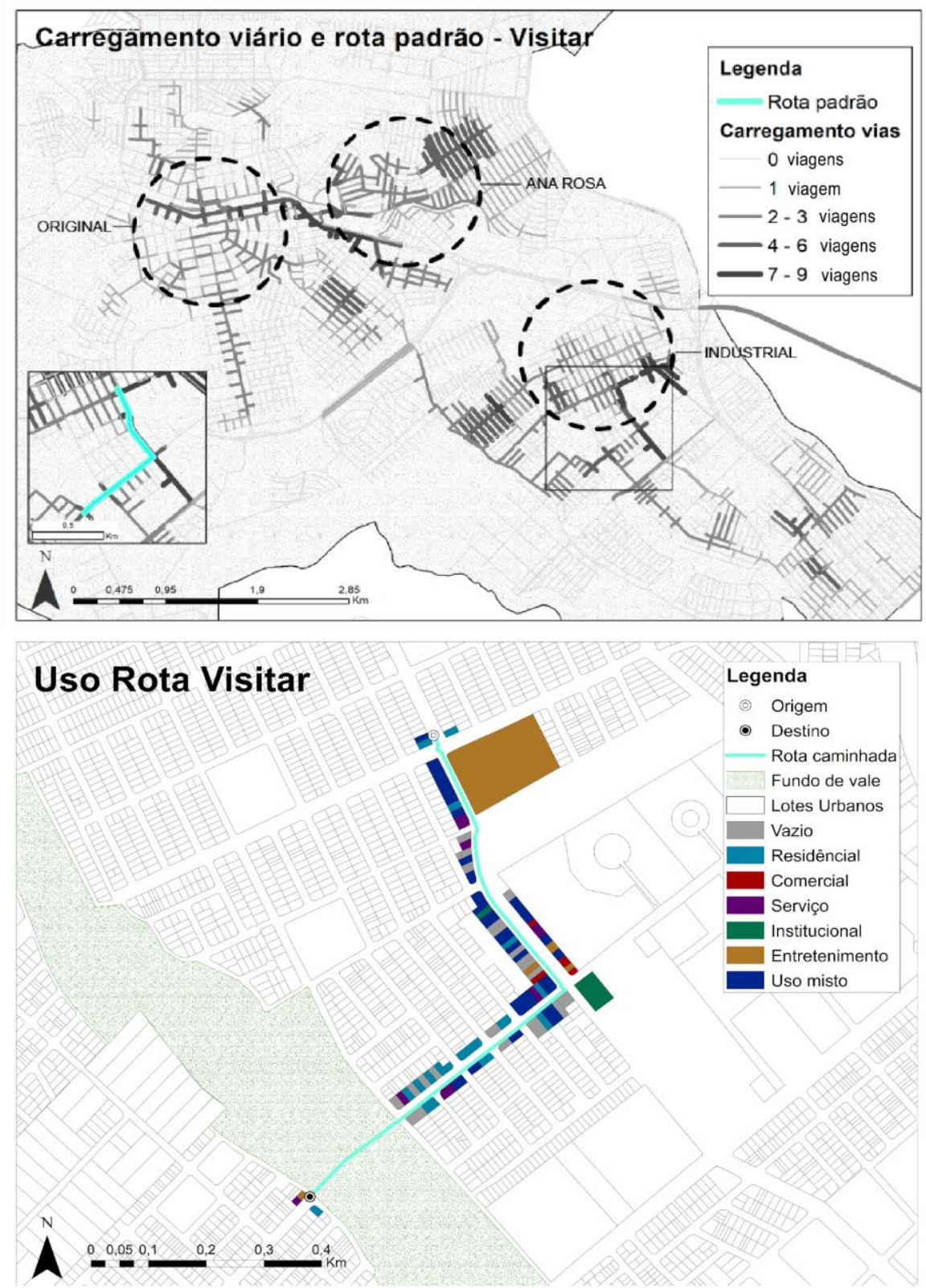

Figura 4. Mapas do propósito "visitar": carregamento viário e localização da rota-padrão (acima) e uso do solo (abaixo) (fonte: PMC, 2020, GP Design Ambiental Urbano, 2020, ITEDES, 2017, sistematizada pelas autoras, 2021).

Para a rota do "visitar" $(1,17 \mathrm{~km})$ (Figura 4), o Nessa rota, o pedestre se desloca por uma remotivo da viagem selecionada foi "lazer". gião menos consolidada, com lotes vazios e 
predominância de uso misto. Segundo Motomura et al. (2018), devido à distância do centro da cidade e a segregação entre rodovia e ferrovia, áreas com maior densidade residencial tendem a melhorar gradualmente suas áreas de varejo, desdobrando-se em um padrão linear de uso misto. Uma característica importante dessa rota é a presença de um fundo de vale, o qual se apresenta como uma barreira física para os pedestres. Por isso, são limitadas as opções de rotas alternativas para a sua travessia, fazendo com que a maior parte dos fluxos da região se concentrem nessas vias.

Além disso, a via que atravessa o fundo de vale conecta o bairro adjacente à rodovia PR445 , condensando os fluxos viários, e por isso, podem desenvolver uma centralidade de bairro e desenvolver um uso do solo mais misto. No contexto de Cambé, essas vias são caracterizadas por uma tipologia em que as edificações possuem dois pavimentos: o térreo, ocupado por usos não-residenciais, como comércio e serviço, e o pavimento superior com uso residencial. Essa configuração oferece ao pedestre a possibilidade de frequentar destinos secundários ao longo da rota. De acordo com Jacobs (2011), os usos primários são aqueles que atraem pessoas a um lugar específico, enquanto os secundários, aproveitam os fluxos já existentes. Nesse caso, o respondente relatou sair de um motivo de "compras" (Uso Misto) para o destino "lazer" (Entretenimento) devido à pequena distância, reforçando a importância da acessibilidade a diversos destinos num raio caminhável.

Os carregamentos das viagens do "morar" (Figura 5) apresentam-se mais distribuídos na malha urbana da cidade em comparação com outros motivos, em que são identificados focos de concentração nos quatro principais núcleos (Original, Ana Rosa, Industrial e Bandeirantes). No núcleo Original, a diversidade de atividades e usos favorece uma formação mista que compreende alguns destinos residenciais. No núcleo Ana Rosa, a barreira física formada pela ferrovia fortalece a formação do aglomerado presente. Já os núcleos In- dustrial e Bandeirantes são áreas que historicamente foram assentadas para projetos de habitação social e, portanto, são caracterizadas por um uso do solo majoritariamente residencial (Motomura et al., 2018). No entanto, os maiores carregamentos se localizam principalmente nas principais vias de acesso à cidade, como a BR-369, onde se localiza a rota selecionada para análise. Ou seja, diferente das outras análises, aqui a concentração de viagens a pé é mais dispersa e não se limita aos principais núcleos da cidade.

Uma análise detalhada da rota "morar" $(1,58$ $\mathrm{km}$ ) (Figura 5), apontou que, próximo à origem e ao destino, seus arranjos espaciais revelam uma predominância residencial, com a presença de alguns usos mistos nos cruzamentos. Já nas proximidades da BR-369, são dispostos lotes de maiores dimensões com usos de serviço e comércio, que atendem à demanda do tráfego rodoviário, mais intenso e de alta velocidade. Na região próxima ao destino, majoritariamente residencial, aparecem mais lotes vazios, indicando ser um bairro em consolidação. É importante notar que a definição desta rota-padrão pode ter sido influenciada pela limitação de pontos de travessia da rodovia, fazendo com que grande parte das rotas georreferenciadas passe por essa via, aumentando seu carregamento.

Nesse caso, o respondente se desloca do motivo "estudar" até sua residência, relatando ser uma pequena distância de acesso, o que representa a importância do acesso aos equipamentos públicos em raios de distâncias caminháveis e acessíveis. Ao contrário do motivo "visitar", percebe-se na rota "morar" uma menor possibilidade de desenvolver atividades secundárias durante o percurso devido à predominância residencial e presença de serviços com foco no fluxo rodoviário. Portanto, infere-se que neste propósito existe uma menor relação entre o uso do solo e a rota, já que os usos presentes não são atrativos aos pedestres, além de apresentar um destino fixo (residência) inserido num contexto de características morfológicas que fornecem poucas possibilidades de caminhos alternativos. 

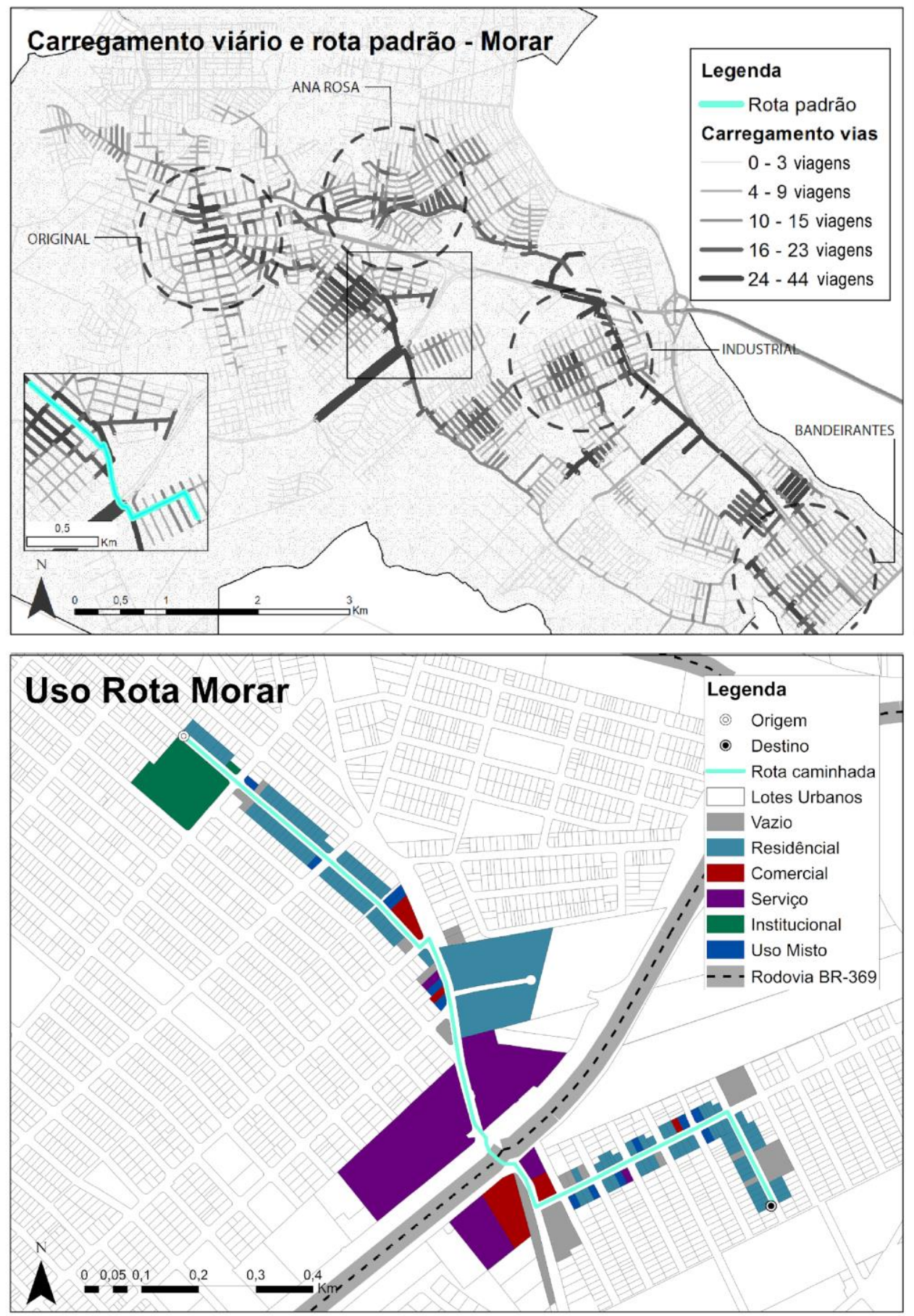

Figura 5. Mapas do propósito "morar": carregamento viário e localização da rota-padrão (acima) e uso do solo (abaixo) (fonte: PMC, 2020, GP Design Ambiental Urbano, 2020, ITEDES, 2017, sistematizado pelas autoras, 2021).

As barreiras físicas estão presentes nas três rotas representativas, o que pode ter influenciado a definição das rotas-padrão. Deve-se considerar que a definição do carregamento viário como critério para seleção dessas rotaspadrão e, inferindo que a presença de barreiras físicas possivelmente gera menor possibilidade de rotas alternativas, os resultados direcionam a seleção para rotas localizadas em vias mais possíveis de transpor essas barreiras. Esse fator também pode estar associado aos propósitos de caminhada, pois como limites físicos tendem a criar zonas mais fechadas (Krafta, 2014), quando o indivíduo se dispõe a acessar certo destino com determinado propósito (principalmente aqueles não-recreativos), pode ser induzido à necessidade de fazer essa transposição, principalmente quando a única 
opção economicamente acessível é a caminhada (Krizek, 2003). Observou-se também a influência de características morfológicas da área de recorte, como a ferrovia ou rodovia, na diversidade do uso do solo do entorno imediato.

A partir da análise dos mapas de uso do solo, também sugere-se que exista uma relação entre uso do solo e o propósito de caminhada, principalmente a presença de usos mistos a qual contribui para o desenvolvimento de propósitos secundários, como observa-se no mapa do "visitar" (Figura 4). Nas rotas analisadas, atividades de caráter mandatório tinham a origem ou o destino em zonas com alto nível residencial. E próximo a barreiras físicas, que são também vias de trânsito intenso, observou-se um desenvolvimento e presença de uso do solo geralmente de serviços ou comercial.

\section{Conclusões}

Esta pesquisa atingiu seu objetivo ao investigar a influência dos diferentes propósitos nas distâncias médias percorridas a pé em um contexto de cidade média brasileira. A análise quantitativa evidenciou que o estudo desenvolvido num contexto de cidade brasileira de médio porte, como Cambé-PR, apresenta resultados diferentes dos encontrados em estudos aplicados em contextos internacionais. Entretanto, acredita-se que, apesar de se tratar de um fenômeno complexo, os resultados alcançados podem contribuir para a compreensão de uma abordagem teórico-metodológica do fenômeno da caminhada num contexto representativo nacional.

Observou-se que propósitos de caráter mandatório e com maiores restrições de tempo admitem comportamentos similares de deslocamento. Entretanto, não é regra que o propósito que apresente o maior valor de distância, também possua maior duração. Este resultado pode estar relacionado às diferentes abordagens dos dados: um é a distância objetiva e outro, a duração percebida. Além disso, também pode sofrer variação de comportamento dos pedestres a cada propósito, por exemplo, a velocidade de deslocamento e a variação da tendência de caminhar certas distâncias.

Ainda, encontrou-se evidências de que a maioria das viagens a pé são realizadas até $800 \mathrm{~m}$ e duram até 15 minutos. Esse resultado pode contribuir para a definição de diretrizes de planejamento urbano, não apenas em Cambé, mas também nas cidades brasileiras de médio porte, oferecendo um suporte para atribuir profundidade e especificidade nos instrumentos que favorecem a caminhabilidade, como a Lei 12.587/2012 da Política Nacional de Mobilidade Urbana. De forma mais prática, pode contribuir por exemplo na localização das escolas num raio de até $1,4 \mathrm{~km}$ ou 15 minutos da residência dos alunos (resultado encontrado no propósito "educação") a fim de incentivar o deslocamento ativo. Recentemente, grandes cidades como Paris, Barcelona e Melbourne têm elaborado estratégias para que os bairros sejam capazes de satisfazer necessidades sociais básicas em distâncias que incentivem comportamentos ativos, como o " 15 - $\mathrm{mi}$ nute city" em Paris e o "20-minute neighbourhoods" em Melbourne. Portanto, esta pesquisa mostra-se atual e alinhada com o que tem sido discutido internacionalmente.

Através da análise espacial, pode-se ter um maior aprofundamento acerca do comportamento de caminhada e sua relação com o ambiente construído. Perceberam-se outras questões associadas ao deslocamento por propósitos, como a possibilidade do desenvolvimento de atividades secundárias no percurso. Os resultados também apontam que os caminhos das rotas selecionadas são traçados de acordo com a conformação das barreiras físicas, como rodovias, ferrovias e fundos de vales, e que áreas isoladas, mais periféricas e distantes dos centros da cidade, podem gerar novas centralidades no bairro. Ademais, em uma situação pandêmica, talvez seja preciso mudanças para uma mobilidade mais sustentável, com foco em atividade lenta, e com mobilidade ativa mais localizada.

Um importante desafio enfrentado foi a busca de uma categorização para desenvolvimento da análise das viagens por propósitos, que teve influência significativa nos resultados. Apesar de não ter sido um objetivo inicial, foi demonstrado que, mesmo utilizando a mesma base de dados, os resultados podem sofrer variações quando agrupados em diferentes escalas. Como limitação, destaca-se que as durações são autorreportadas e representam percepções dos indivíduos, e que as rotas utilizadas para os cálculos foram traçadas a partir de dados secundários, podendo apresentar impre- 
cisão nos resultados. Ademais, os dados disponíveis não permitiram análise dos perfis sociodemográficos dos pedestres, mas sugere-se o aprofundamento desta discussão em pesquisas futuras, assim como explorar outras formas de traçar a rota em questionários, como o uso de sistemas de geolocalização possivelmente considerando a influência do relevo.

\section{Referências}

Adlakha, D. e Sallis, J. F. (2020) Activityfriendly neighbourhoods can benefit non-communicable and infectious diseases. Cities \& Health. 1-5. Disponível em: https://doi.org/10.1080/23748834.2020.17834 79

Agrawal, A. W., Schlossberg, M. e Irvin, K. (2008) How far, by which route and why? A spatial analysis of pedestrian preference. Journal of Urban Design, 13(1), 81-98. Disponível em: https://doi.org/10.1080/13574800701804074.

Bauman, A. E., Reis, R. S., Sallis, J. F., Wells, J. C., Loos, R. J. F. e Martin, B.W. (2012) Correlates of physical activity: Why are some people physically active and others not? Lancet 380, 258-271. Disponível em: https://doi.org/10.1016/S01406736(12)60735-1.

Cambra, P. e Moura, F. (2020) How does walkability change relate to walking behavior change? Effects of a street improvement in pedestrian Vols. and walking experience. Journal of Transport \& Health. 16, 100797. Disponível em: https://doi.org/10.1016/j.jth.2019.100797.

CNI-Ibope (2015) Retratos da sociedade brasileira: Mobilidade urbana. Disponível em: https://www.portaldaindustria.com.br/estatisticas/rsb-27-mobilidade-urbana/. [Consultado em: 24 de novembro de 2020].

Congress for the New Urbanism (CNU) (2019). Disponível em: https://www.cnu.org/who-we-are/charter-newurbanism. [Consultado em: 14 de dezembro de 2019].

Dean, J., Biglieri, S., Drescher, M., Garnett, A., Glover, T. e Casello, J. (2020) Thinking relationally about built environments and

\section{Agradecimentos}

À Fundação Araucária, pelo financiamento da bolsa concedida para a realização da iniciação científica (2019/2020), à Capes/Fundação Araucária pelas bolsas de mestrado e pós-doutorado, à Capes pela bolsa de doutorado e ao grupo de Pesquisa Design Ambiental Urbano.

walkability: A study of adult walking behavior in Waterloo, Ontario. Health and Place. 64(June), 102352. Disponível em: https://doi.org/10.1016/j.healthplace.2020.102352.

Dewulf, B., Neutens, T.; van Dyck, D.; de Bourdeaudhuij, I.; de Weghe, N. (2012) Correspondence between objective and perceived walking times to urban destinations: Influence of physical activity, neighbourhood walkability, and socio-demographics. International Journal of Health Geographics. 11(46). Disponível em: http://www.ij-healthgeographics.com/content/11/1/43. [Consultado em: 16 de outubro de 2020].

Dovey, K. e Pafka, E. (2017) What is functional mix? An assemblage approach, Planning Theory and Practice. 18(2), 249-267. Disponível em: https://doi.org/10.1080/14649357.2017.12819 96.

Duncan, M. J., Winkler, E., Sugiyama, T., Cerin, E., duToit, L., Leslie, E. e Owen, N. (2010) Relationships of land use mix with walking for transport: Do land uses and geographical scale matter? Journal of Urban Health. 87(5), 782-795. Disponível em: https://doi.org/10.1007/s11524-010-9488-7.

Ewing, R. e Cervero, R. (2010) Travel and the built environment. Journal of the American Planning Association, 76(3), 265-294. Disponível em: https://doi.org/10.1080/01944361003766766.

Frank, L. D., Sallis, J. F., Saelens, B. E., Leary, L., Cain, K., Conway, T. L. e Hess, P. M. (2010) The development of a walkability index: Application to the neighborhood quality of life study. British Journal of Sports Medicine. 44(13), 924-933. Disponível em: https://doi.org/10.1136/bjsm.2009.058701.

Fonseca, F.; Conticelli, E.; Papageorgiou, G.; Ribeiro, P.; Jabbari, M.; Tondelli, S.; Ramos, 
R. (2021) Levels and Characteristics of Utilitarian Walking in the Central Areas of the Cities of Bologna and Porto. Sustainability, 13(6), 3064. Disponível em: https://doi.org/10.3390/su13063064.

Gim, T. H. T. (2011) A comparison of the effects of objective and perceived land use on travel behavior. Growth and Change, 42(4), 571-600. Disponível em: https://doi.org/10.1111/j.1468-

2257.2011.00568.x.

Guimarães, K., Leão, A. L. F., Urbano, M. R. e Kanashiro, M. (2019) Percepções do ambiente construído e sua associação com a caminhabilidade objetiva. Revista de Morfologia Urbana, 7(2). Disponível em:

https://doi.org/10.47235/rmu.v7i2.84.

Gunn, L. D., King, T. L., Mavoa, S., Lamb, K. E., Giles-Corti, B. e Kavanagh, A. (2017) Identifying destination distances that support walking trips in local neighborhoods. Journal of Transport and Health. 5, 133-141. Disponível em:

https://doi.org/10.1016/j.jth.2016.08.009.

Guzman, L. A., Peña, J. e Carrasco, J. A. (2020) Assessing the role of the built environment and sociodemographic characteristics on walking travel distances in Bogotá. Journal of Transport Geography. 88, 102844. Disponível em:

https://doi.org/10.1016/j.jtrangeo.2020.10284 4.

Hamidi, S., Sabouri, S. e Ewing, R. (2020) Does density aggravate the COVID-19 pandemic? Journal of the American Planning Association. 86(4), 495-509. Disponível em: https://doi.org/10.1080/01944363.2020.17778 91.

Hatamzadeh, Y., Habibian, M. e Khodaii, A. (2014) Walking behavior by trip purpose. Journal of the Transportation Research Board. 2464, 118-125. Disponível em: https://doi.org/10.3141/2464-15.

Hino, A. A. F., Reis, R. S. e Florindo A. A. (2010) Ambiente construído e atividade física: uma breve revisão dos métodos de avaliação. Revista Brasileira de Cineantropometria \& Desempenho Humano. 12(5), 387-394. Disponível em: https://doi.org/10.5007/19800037.2010V12N5P387.
Iacono, M., Krizek, K. e El-Geneidy, A. (2008) Access to Destinations: How Close is Close Enough? Estimating Accurate Distance Decay Functions for Multiple Modes and Different Purposes. Access to Destinations Study. 4, 76. Disponível em: https://doi.org/10.1111/1467-6494.00086.

Instituo Brasileiro de Geografia e Estatística (IBGE) (2020) Estatísticas por cidade e estado. Disponível em: https://www.ibge.gov.br/cidades-e-estados/pr/cambe.html?. [Consultado em: 13 de dezembro de 2019].

Instituto Brasileiro de Geografia e Estatística (IBGE) (2010) Downloads - Organização do território: Malhas territoriais. Disponível em: https://www.ibge.gov.br/geociencias/organizacao-do-territorio/malhas-territoriais.html. [Consultado em: 08 de julho de 2021].

Instituto de Tecnologia e Desenvolvimento Econômico e Social (ITEDES) (2017) PlanMob: Plano Municipal de Mobilidade Urbana de Cambé-PR. Disponível em:

http://www.cambe.pr.gov.br/site/panomoburbana/documentosplanomobilidade/cat_view/449-planomobilidade.html. [Consultado em: 19 de fevereiro de 2019].

Jacobs, J. (2011) Morte e vida de grandes cidades. $2^{a}$ edição. São Paulo, Martins Fontes. (Publicado originalmente em 1961).

Krafta, R. (2014) Notas de Aula de Morfologia Urbana. $1^{\text {a }}$ edição. Porto Alegre, Editora UFRGS.

Krizek, K. J. (2003) Neighborhood services, trip purpose, and tour-based travel. Transportation. 30(4), 387-410. Disponível em: https://doi.org/10.1023/A:1024768007730.

Lamour, Q., Morelli, A. M. e Marins, K. R. d. C. (2019) Improving walkability in a TOD context: Spatial strategies that enhance walking in the Belém neighbourhood, in São Paulo, Brazil. Case Studies on Transport Policy. 7(2), 280-292. Disponível em: https://doi.org/10.1016/j.cstp.2019.03.005.

Larranaga, A. M. e Cybis, H. B. B. (2014) The relationship between built environment and walking for different trip purposes in porto alegre, Brazil. International Journal of Sustainable Development and Planning, 9(4), 568-580. Disponível em: https://doi.org/10.2495/SDP-V9-N4-568-580. 
Larsen, J., El-Geneidy, A. e Yasmin, F. (2010) Beyond the Quarter Mile: Re-examining Travel Distances by Active Transportation. Canadian Journal of Urban Research: Canadian Planning and Policy (supplement), 19(1), 70-88. Disponível em:

https://www.jstor.org/stable/26193275. [Consultado em: 16 de dezembro de 2020].

Leão, A. L. F., Abonizio, H. Q., Reis, R. S., Kanashiro, M. (2020) Walkability variables: an empirical study in Rolândia - PR, Brazil. Ambiente Construído. 20(2), 475-488. Disponível em: https://doi.org/10.1590/s167886212020000200410.

Lee, C. e Moudon, A. V. (2006) The 3Ds + R: Quantifying land use and urban form correlates of walking. Transportation Research Part D: Transport and Environment. 11(3), 204-215. Disponível em: https://doi.org/10.1016/j.trd.2006.02.003.

Lopes, A. A. S., Kienteka, M., Fermino, R. C. e Reis, R. S. (2018) Características da microescala do ambiente, caminhada e uso de bicicleta no deslocamento em adultos de Curitiba, Paraná, Brasil. Caderno de Saúde Pública. 34(1), e00203116. Disponível em: https://doi.org/10.1590/0102$311 \mathrm{Xe} 00203116$.

Millward, H., Spinney, J. e Scott, D. (2013) Active-transport walking behavior: Destinations, durations, distances. Journal of Transport Geography. 28, 101-110. Disponível em: https://doi.org/10.1016/j.jtrangeo.2012.11.012

Mirzaei, E., Kheyroddin, R., Behzadfar, M. e Mignot, D. (2018) Utilitarian and hedonic walking: examining the impact of the built environment on walking behavior. European Transport Research Review. 10(2). Disponível em: https://doi.org/10.1186/s12544-018-0292$\mathrm{x}$.

Mondschein, A. (2018) Persistent Differences in Walking across the Socioeconomic Spectrum: Variations by Trip Purpose. Journal of Planning Education and Research, 41(4), pp. 445-460. Disponível em: https://doi.org/10.1177/0739456X18796652.

Motomura, M. C. N., Fontoura, L. C. e Kanashiro, M. (2018) Understanding walkable areas: applicability and analysis of a walkability index in a Brazilian city. Ambiente Construído. 18(4), 413-425. Disponível em: https://doi.org/10.1590/s167886212018000400313.

Musselwhite, C., Avineri, E. e Susilo, Y. (2021) Restrictions on mobility due to the coronavirus Covid19: Threats and opportunities for transport and health. Journal of Transport \& Health, 20(101042). Disponível em: https://doi.org/10.1016/j.jth.2021.101042.

Nakamura, P. Papini, C., Teixiera, I., Fernandes, R. e Kokubun, E. (2014) Associação da caminhada no lazer e no transporte com ambiente construído em adultos do município de Rio Claro-SP. Revista Brasileira de Atividade Física \& Saúde. 18(4), 424-434. Disponível em:

https://doi.org/10.12820/rbafs.v.18n4p424.

Perchoux, C., Brondeel, R., Wasfi, R., Klein, O., Caruso, G., Vallée, J., Klein, S., Thierry, B., Dijst, M., Chaix, B., Kestens, Y. e Gerber, P. (2019) Walking, trip purpose, and exposure to multiple environments: A case study of older adults in Luxembourg. Journal of Transport and Health. 13(August 2018), 170184. Disponível em: https://doi.org/10.1016/j.jth.2019.04.002.

Prefeitura do Município de Cambé (PMC) (2020) Base cartográfica.

Rego, R. L. e Meneguetti, K. S. (2008) O Território e a Paisagem: a formação da rede de cidades do Norte do Paraná e a construção da forma urbana. Paisagem Ambiente: ensaios. 25, 37-54. Disponível em: https://doi.org/10.11606/issn.23595361.v0i25p37-53.

Saelens, B. E., Sallis, J. F. e Frank, L. D. (2003) Environmental correlates of walking and cycling: Findings from the transportation, urban design, and planning literatures. Annals of Behavioral Medicine. 25(2), 80-91. Disponível em: https://doi.org/10.1207/S15324796ABM2502 _03.

Sallis, J. F. e Glanz, K. (2009) Physical activity and food environments: Solutions to the obesity epidemic. Milbank Quarterly. 87(1), 123-154. Disponível em: https://doi.org/10.1111/j.14680009.2009.00550.x.

Sallis J. F., Bull F., Burdett R., Frank L. D., Griffiths P., Giles-Corti B. e Stevenson, M. (2016) Use of science to guide city planning 
policy and practice: how to achieve healthy and sustainable future cities. Lancet. 388(10062):2936-2947. Disponível em: https://doi.org/10.1016/S01406736(16)30068-X.

Scheepers, E., Slinger, M., Wendel-Vos, W. e Schuit, J. (2014) How combined trip purposes are associated with transport choice for short distance trips. Results from a cross-sectional study in the Netherlands. PLoS ONE, 9(12), 1-14. Disponível em: https://doi.org/10.1371/journal.pone.0114797.

Silveira, R. (1989) Planejamento Urbano Participativo: a experiência de Cambé. Londrina, Universidade Estadual de Londrina.

Song, Y., Merlin, L. e Rodriguez, D. (2013) Comparing measures of urban land use mix. Computers, Environment and Urban Systems. 42, 1-13. Disponível em: http://dx.doi.org/10.1016/j.compenvurbsys.2013.08.001.

Southworth, M. (2005). Designing the Walkable City. Journal of Urban Planning and Development. 131(4), 246-257. Disponível em: https://doi.org/10.1061/(ASCE)07339488(2005)131:4(246).

Sugiyama, T., Neuhaus, M., Cole, R., GilesCorti, B. e Owen, N. (2012) Destination and route attributes associated with adults' walking: A review. Medicine and Science in Sports and Exercise. 44(7), 1275-1286. Disponível em:
https://doi.org/10.1249/MSS.0b013e318247d2 86.

Tian, G. e Ewing, R. (2017) A walk trip generation model for Portland, OR. Transportation Research Part D: Transport Environment. 52, 340-353. Disponível em: http://dx.doi.org/10.1016/j.trd.2017.03.017.

Vale, D. S., Saraiva, M., e Pereira, M. (2016). Active accessibility: A review of operational measures of walking and cycling accessibility. Journal of Transport and Land Use, 9(1). Disponível em: https://doi.org/10.5198/jtlu.2015.593.

Yamaki, H. (2017) Terras do Norte: paisagem e morfologia. Londrina, Editor Humberto Yamaki / UEL.

Yang, Y., Heppenstall, A., Turner, A. e Comber, A. (2019) Who, where, why and when? Using smart card and social media data to understand urban mobility. ISPRS International Journal of Geo-Information, 8(6). Disponível em: https://doi.org/10.3390/ijgi8060271.

Yang, Y. e Diez-Roux, A. V. (2012) Walking distance by trip purpose and population subgroups. American Journal of Preventive Medicine. 43(1), 11-19. Disponível em: https://doi.org/10.1016/j.amepre.2012.03.015.

Yin, R. K. (2001) Estudo de caso: Planejamento e Métodos. $2^{\circ}$ ed. São Paulo, Bookman Companhia Editora. 


\section{Tradução do título, resumo e palavras-chave}

Walking for different purposes: a study in the city of Cambé-PR

Abstract. Walking is a socially equitable and economically viable mode of transportation, which can be influenced by several factors and domains. Evidence indicates that different walking purposes are associated with different characteristics of the built environment, such as the diversity of land uses. Therefore, it is necessary to deepen the focus on why people choose to commute by foot. The objective of this research is to analyze walked routes for different purposes, based on distance, duration and land use data. The Case Study was adopted as a methodological strategy in the city of Cambé-PR and, as a tactic, a correlational analysis was conducted through quantitative and spatial procedures. The results indicate that the purposes exert great influence on walking behavior and that mandatory functions generally have similar behaviors. Furthermore, the gathered evidence indicates that most trips by foot are up to 800 meters and last up to 15 minutes. The research contributes so that spatial areas of influence can be identified, serving as parameters for urban intervention strategies that support active behaviors.

Keywords: built environment, walkability, trip purpose.

Editor responsável pela submissão: Vinicius M. Netto.

Licenciado sob uma licença Creative Commons.

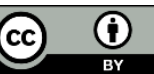

